\title{
Research on the Relationship between Logistics Industry Energy Consumption and Economic Development in Shanghai
}

\author{
Chen Wei \\ Economics and Management School \\ Shanghai Second Polytechnic University \\ Shanghai, China \\ chenw@sspu.edu.cn
}

\author{
Li Hehua \\ Economics and Management School \\ Shanghai Second Polytechnic University \\ Shanghai, China \\ hhli@sspu.edu.cn
}

\begin{abstract}
Logistics industry is an important part of the national economy, but also is of the large industries for energy consumption. This study analyzes the relationship between economic output and logistics' energy consumption in Shanghai during the period 1998 to 2012 . The results show that the regression equation is similar with environmental Kuznets curve, showing an inverted $U$-shaped curve. The results show that the regression equation is similar with environmental Kuznets curve, showing an inverted U-shaped curve. The process of relationship between economic developments of the logistics industry energy consumption indicates from worsening to improvement. Energy consumption in Logistics industry will be reduced as the economy consumption incensement. However, it must pay attention to control the rapid growth in energy consumption and achieve the development mode of low growth rate in energy consumption.
\end{abstract}

Keywords- Shanghai; energy; logistics; economic growth; relationship

\section{INTRODUCTION}

Global warming caused by greenhouse effect has become the focus for all countries. The International Energy Agency has listed China as one of the leading carbon dioxide emitters and the Chinese government attaches great importance and promises to the world "China carbon dioxide emissions per unit of GDP in2020 decrease by $40 \%-45 \%$ compared to that in 2005 . Shanghai is China's economic centre and the logistics industry is an important part of the national economy. It will be of great realistic significance in the establishment of an international economic, financial, trade and shipping centre. The energy consumption of logistics industry is obvious, therefore analysis of the trend of energy consumption of logistics industry in Shanghai as well as the relationship between energy consumption and economic growth in the city, will help policymaker's choices in order to achieve a low-carbon economy.

This paper established theoretically regression equations of the relationship between logistics industry energy consumption and economic activity of Shanghai, which similar to the concept of environmental economics curve (EKC) [1] in order to supply the theoretic proof for the energy conservation and reduction of pollutant emissions.

The paper is organized as follows. In the next section, we propose the relationship regression model. In Section 3, empirical analysis is presented and the regression analysis is made to illustrate the relationship between the economic activity and logistic energy consumption. Finally, we conclude the paper in section 4.

\section{RELATIONSHIP REGRESSION METHODS}

\section{A. Method of Environmental Kuznets Curve}

Environmental Kuznets Curve (EKC) [2-5] is an important hypothesis which indicates that relationship between the levels of economic activity ( for example, per capita income) and the environmental burden (for example, industrial and urban household wastewater) with an inverted U-shaped curve. Particularly during the early stage of economic development, the trend of the deterioration of ecological environmental quality was significant. At a more advanced stage of economic development, the economic activity improved environmental quality, that is the rate of deterioration of environmental quality in the early stages of economic development faster than economic growth and rate of environmental degradation is slower than the rate of economic growth when the economic activity growth to a certain extent.

The US environmental economists Grossman and Krueger estimated the reduced form relationship between income and various measures of environmental degradation and give the concept of Environmental Kuznets curve which was used to analysis the level of economic development. In the environmental Kuznets curve, environmental pollution levels as variable changed by per capita income increase. Since Grossman and Krueger had proposed the hypothesis of EKC curve, the environmental economic theory is getting constant development and the EKC empirical studies have grown rapidly. For instance, Su et al analyzed the economic and environmental data from 1990 to 2010 of Taizhou and 
found environmental quality does not improved automatically with the city per capita GDP increase, which indicated it is different from the typical Environmental Kuznets curve [6]. OUYANG and TU used the Environmental Kuznets curve test to study the relationship between industry waste of the upper Yangtze River and the GDP indicator, which had been found some pollutants with different turning point [7].Fu, et al used the Environmental Kuznets curve to analyzes the relationship between air quality and economic development in Baoji city. It was be found in the period 2006 to 2011, the air quality has been improved with the growth of economy, and the relationship was developed in the declining part of the turning point of inverted U type curve [8]. Liu and Meng used the EKC method to study the relationship between economic activity and energy-related carbon emissions of Yunnan province and found that the relationship curve was a linear rather than the inverted $U$ [9]. Lin analyzed the relationship between per capita GDP and carbon dioxide emissions in Wuhan in the period of 1996 to 2011 and the results showed the relationship curve was the inverted $U$ and the carbon dioxide emissions would increase currently [10]. Zhao, et al. use the EKC theory to construct the relationship between per capita GDP and China's energy consumption in the period of 1955 to 2010 and the results showed the cubic curve[11].

\section{B. Definition of the logistic Industry and data resource}

The logistic Industry in this study is limit to the transportation warehousing post services and energy consumption data is the final energy consumption with equivalent of standard coal. The collection of GDP, energy consumption data are from the Statistical Yearbook and Shanghai Industrial Energy Transportation Energy Statistics Yearbook.

\section{Regression equations}

EKC regression equation includes an independent variable $\mathrm{x}$ and dependent variable $\mathrm{y}$, as shown in Equation 1.

$$
\mathrm{y}=c+\beta_{1} x+\beta_{2} x^{2}+\beta_{3} x^{3}+\varepsilon
$$

It could get some different type of fitted regression line, such as U-type, N-type, etc and then choose the best-fit one among function of quadratic function 、 cubic function 、 logarithmic function 、 exponential functions, etc. The values of $R^{2}$ and $F$ were the primary reason for selecting the appropriate curve. Essentially, the regression analysis as a method was used to describe for quantitative analysis of causal relationships between variables. The dependent variable $\mathrm{Y}$, whose value depends on the value of an independent variable, could be an explanation of the impact of variables $X$. In order to select the most appropriate regression curve between Shanghai Logistics carbon dioxide emissions and economic output, the study used Eview to establish regression models, including linear, quadratic and cubic regression as follows: Equation2-4.

$$
\begin{gathered}
\mathrm{e}=c+\beta_{1} \mathrm{~g}+\varepsilon \\
\mathrm{e}=c+\beta_{1} \mathrm{~g}+\beta_{2} \mathrm{~g}^{2}+\varepsilon \\
\mathrm{e}=c+\beta_{1} \mathrm{~g}+\beta_{2} \mathrm{~g}^{2}+\beta_{3} \mathrm{~g}^{3}+\varepsilon
\end{gathered}
$$

\section{EKC EMPIRICAL ANALYSIS}

\section{A. Trend of economic growth}

Shanghai economy is developed rapidly between 1998 and 2012, rising from 380.1 billion Yuan in 1998 to 2.0182 trillion Yuan in 2012 with an average annual increase rate of up to $12.7 \%$. The highest value appeared in the year 2004 reaching 20.6\%.Meanwhile, the growth rate of energy consumption in the logistics industry was also evident which was from the 4.6 million tons of standard coal in 1998 to 20.46 million tons of standard coal in 2012, with an average annual growth rate of $11.6 \%$,as shown in Fig.1.The highest value also appeared in 2004 reached $31.6 \%$.However, the growth rate of energy Consumption slowed down significantly since 2008, with the average rate only $2.3 \%$.The rate in year of 2011 even was a negative increase and energy Consumption of Logistics industry grew at low speed during this period.

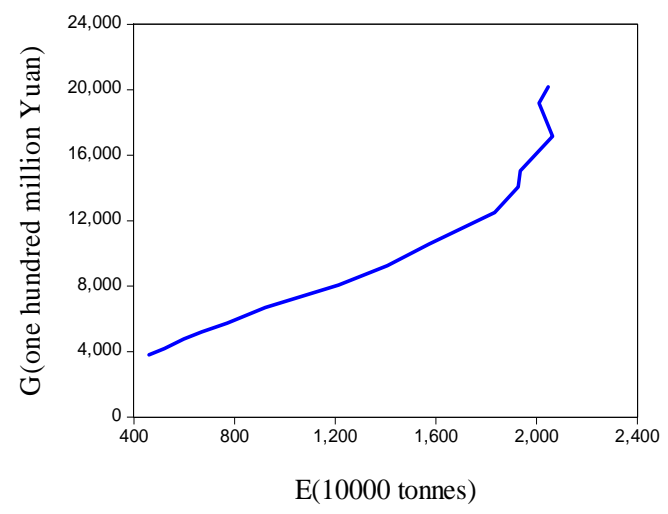

Figure 1. Trend of energy consumption and economy

\section{B. The caculation of three types of regression curves}

Three types of regression curves were as shown in Fig.2, Fig.3 and Fig.4.Through the analysis on the regression results, the quadratic equations about economic activity change with energy consumption were estimated which show as Equation 5

$$
\begin{aligned}
& E=-566.50+0.2830 G-7.641 e^{-6} G^{2} \\
& R^{2}=0.996 \text { D.W }=1.28 \text { se }=39.45 F=1737.8
\end{aligned}
$$

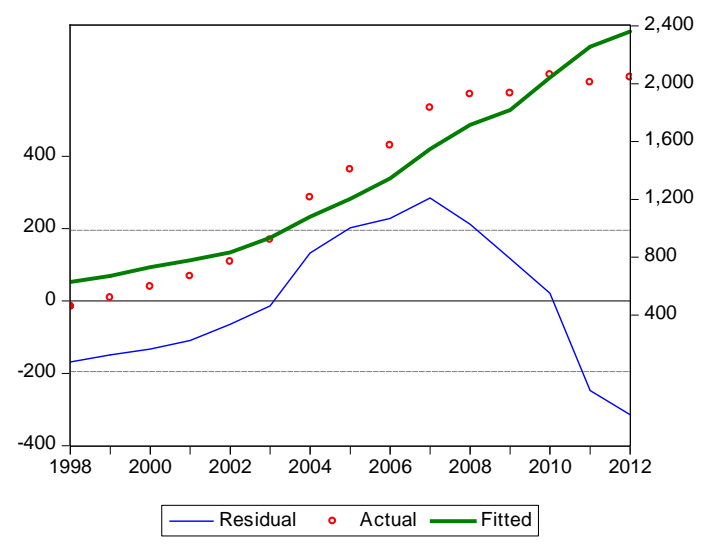

Figure 2. Curve of E-G regression 


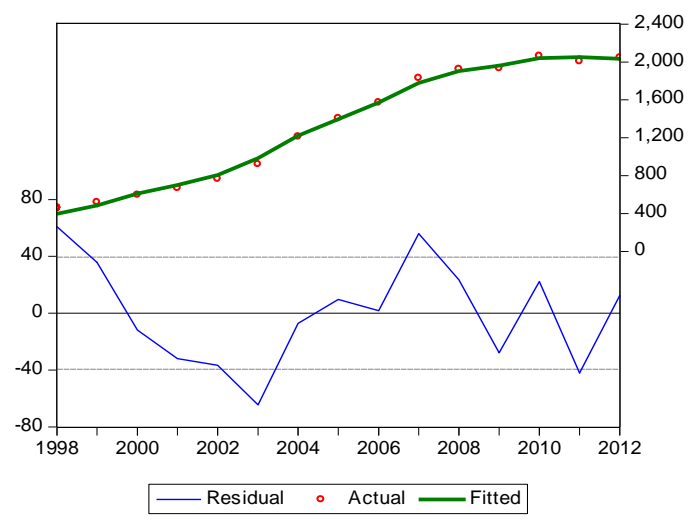

Figure 3. Curve of $\mathrm{E}-\mathrm{G}^{2}$ regression

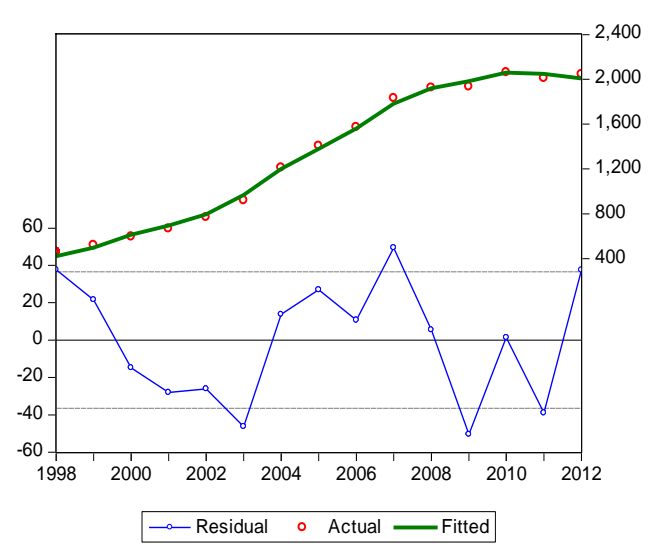

Figure 4. Curve of ${\mathrm{E}-\mathrm{G}^{3}}^{3}$ regression

\section{Empirical Analysis}

The typical E-G ${ }^{2}$ quadratic function for the analysis of GDP and Energy was illustrated in Fig.3. The curve of relationship between Shanghai GDP and energy consumption in logistics industry showed inverted Ushaped, which was similar to the environmental Kuznets hypothesis. The value of $\mathrm{R}^{2}$ was 0.996 and indicated the better fitting result, which showed economic activity is an important factor affecting the logistics industry energy consumption change. In early stage of economic development and low level of urban economic output, the energy consumption of the logistics industry increased with the growth of the GDP, while economic output increased to a certain extent, the level of energy consumption in logistic Industry would tend to reduce simultaneously. Logistics energy consumption showed dynamic process- worsening - process improvement with economic increase. Inflection Point of the inverted Ushaped curve was the year 2010 and energy consumption was 20.63 million tons of standard coal, GDP was 1.72 trillion Yuan, as shown in Fig. 3. When GDP exceeds this extreme value, the energy consumption trends would show reduced trend. Per capita GDP in 2010 was about 121,500 Yuan, which indicated that the logistic Industry in Shanghai achieved to limit the growth rate of energy consumption and Shanghai logistics industry had enhanced energy efficiency.

The trend of energy consumption in logistic sectors is similar to the Environmental Kuznets curve, which indicated that the logistics industry energy consumption keep pace with the rising level of economic activity and decrease when economic growth reached an inflection point. the current stage is the turning point , specifically, that in the early economic developing period, energy consumption will be increasing as the economy grows; and when economic development reaches a certain height, energy consumption will decrease as the economy still increases. It can be seen from the Fig.3 when the per-capita GDP will exceed 121,500 Yuan the theoretical EKC assumptions of the inflection point occurs in Shanghai, but it should be noted that the period of inflection point may be longer and the precondition for the inflection point assumption in this discussion is that decoupling development between the energy consumption of logistics industry and urban economic growth. With the high-speed development of economy and suppliers, customers, trades also promote the logistic industry; the level of energy consumption will continued to rise. No doubt, EKC hypothesis is only a data empirical analysis of economic development and environmental pollution, and does not reflect the real environmental conditions change. Even the year of 2010 was the theoretical turning point, it must continue to implement strong energy conservation policy to limit the energy consumption increase.

It is difficult to judge the actual consumption trend of energy with currently control policy. The hypothesis of Environmental Kuznets curve merely indicated a theoretical proof of inflection between economic activity and energy consumption in logistic sectors. The government should make particular policy from the perspective of management costs and political feasibility which means that policymaker should also take into account the objective of developing the economy. Limit the growth rate of energy consumptions will be scientifically energy conservation policy.

\section{CONCLUSIONS}

The purpose of the study is to analysis the relationship between economic output and logistics energy consumption in Shanghai. It used the regression models for GDP and energy consumption including linear function, quadratic function and cubic function. The empirical results show that curve of $E-G^{2}$ regression is typical Inverted U-shaped which is similar to EKC hypothesis and the year 2010 was the important turning point. The theoretical Environmental Kuznets curve assumptions of the turning point occurred when Shanghai's per capita GDP reached the value of 121,500Yuan. Energy consumption of Shanghai logistics industry would gradually reduce theoretically.

\section{ACKNOWLEDGMENT}

This paper is supported by Innovation Program of Shanghai Municipal Education Commission (GrantNo.14YS141) and Foundation of Shanghai Second Polytechnic University Grant No.A30NH1409020 and A30NH1409180) 


\section{REFERENCES}

[1] S. Dinda, “ Environmental Kuznets Curve Hypothesis: A Survey. Ecological Economics,”49(4), pp. 431-455, 2004.

[2] Chen Wenhua,Liu Kangbing. "Economic Growth and Environmental Quality: An Empirical Analysis of the Environmentel Kuznets Curve,” Fudan Journal (Social Sciences Edition) , 2, pp.88-94, 2004.

[3] Dinda. S, "A Theoretical Basis for the Environmental Kuznets Curve,” Ecological Economics, 53 ,pp.403-413, 2005.

[4] D.I. Stern, "The Rise and Fall of the Environmental Kuznets Curve,”World Development, 32(8),pp. 1419-1439, 2004.

[5] He Jie,Wang Hua, "Economic Structure, Development Policy and Environmental Quality An Empirical Analysis of Environmental Kuznets Curves with Chinese Municipal Data,” Ecological Economics, 76,pp.49-59, 2012.

[6] Su Wei , Tan Lingyan, Hu Zenghui, et al, “Analysis on Relationship between Economic Growth and Environmental
Pollution in Taizhou City," Environmental Science and Management,39(6),2014,pp. 70-72.

[7] OuYang Wanghua, TU Liangjun, "EKC Test and Analysis on Industrial Pollution in the Upper Yangtze River Industrial:Based on Logistic,” Ecological Economy, 30(10) ,2014,pp. 164-169.

[8] Fu Chunping, Wang Lizhang , Zhong Jiabo, et al, "Study on Relationship between Economic Growth and Comprehensive Index of Air Pollution in Baoji,"Environmental Science and Management,39(4) ,2014,pp.52-54.

[9] Liu Jiwang, Meng Yanju, "Analysis of the Relationship between Economic Growth and Carbon Emissions,” Review of Industry Economics,4,2014,pp. 44-53.

[10] Lin Shen, "Growth of Low-Carbon City and Sustainable Development of Economy: Empirical Studies of Carbon Emissions Environment Kuznets Curve in Wuhan,”Ecological Economy,30(7) ,2014,pp. 98-100.

[11] Zhao Aiwen, He Ying,Wang Shuang-ying,et al, "EKC Test for China ' s Energy Consumption and the Impact Factors Analysis”Systems Engineering Theory Methodology Applications, 23(3) ,2014,pp. 416-422. 